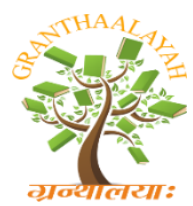
INTERNATIONAL JOURNAL OF RESEARCH
GRANTHAALAYAH
A knowledge Repository

Science

\title{
A LOGISTIC NONLINEAR BLACK-SCHOLES-MERTON PARTIAL DIFFERENTIAL EQUATION: EUROPEAN OPTION
}

\author{
Joseph Otula Nyakinda *1 \\ ${ }^{*}$ School of Mathematics and Actuarial Science, Jaramogi Oginga Odinga University of Science \\ and Technology, Kenya
}

\begin{abstract}
Nonlinear Black-Scholes equations provide more accurate values by taking into account more realistic assumptions, such as transaction costs, illiquid markets, risks from an unprotected portfolio or large investor's preferences, which may have an impact on the stock price, the volatility, the drift and the option price itself. Most modern models are represented by nonlinear variations of the well-known Black-Scholes Equation. On the other hand, asset security prices may naturally not shoot up indefinitely (exponentially) leading to the use of Verhulst's Logistic equation. The objective of this study was to derive a Logistic Nonlinear Black Scholes Merton Partial Differential equation by incorporating the Logistic geometric Brownian motion. The methodology involves, analysis of the geometric Brownian motion, review of logistic models, process and lemma, stochastic volatility models and the derivation of the linear and nonlinear Black-Scholes-Merton partial differential equation. Illiquid markets have also been analyzed alongside stochastic differential equations.

The result of this study may enhance reliable decision making based on a rational prediction of the future asset prices given that in reality the stock market may depict a nonlinear pattern.
\end{abstract}

Keywords: Non-Linear; Black Scholes; Brownian Motion; Logistic Brownian Motion; Illiquid Markets.

Cite This Article: Joseph Otula Nyakinda. (2018). "A LOGISTIC NONLINEAR BLACKSCHOLES-MERTON PARTIAL DIFFERENTIAL EQUATION: EUROPEAN OPTION.” International Journal of Research - Granthaalayah, 6(6), 480-487. https://doi.org/10.29121/granthaalayah.v6.i6.2018.1393.

\section{Introduction}

\section{Logistic Geometric Brownian Motion Model}

In relaxing one of the assumptions of the Black-Scholes-Merton partial differential equation and using the Walrasian law and the excess demand function $E D(S(t))=Q_{D}(S(t))-Q_{S}(S(t))$, where $E D(S(t))$ represents the excess demand, $Q_{D}(S(t))$ and $Q_{S}(S(t))$ are the quantities demanded and supplied respectively, the price of an asset follows a logistic geometric Brownian motion given by equation; 


$$
\begin{aligned}
& d S-\mu S\left(S^{*}-S\right) d t+\sigma S\left(S^{*}-S\right) d Z \\
& \frac{1}{S} \frac{d S}{\left(S^{*}-S\right)}=\mu d t+\sigma d Z
\end{aligned}
$$

Where $S^{*}$ is the Walrasian market equilibrium price, $S$ is the stock price at any given time $t, \mu$ is the drift rate and $\sigma$ is the volatility of the stock price at any given time $t$. Here, volatility $\sigma$ is constant, [37].

We use the Logistic Geometric Brownian Motion in equation (1) and a choice of portfolio in equation $\Pi=-C+\frac{\partial C}{\partial S} S$ and the change in portfolio equation $\delta \Pi=-\delta C+\frac{\partial C}{\partial S} \delta S$ to derive to derive the Logistic Black-Scholes-Merton Partial differential equation give as,[37]

$$
\frac{\partial C}{\partial t}+r S(S *-S) \frac{\partial C}{\partial S}+\frac{1}{2} \sigma^{2} S^{2}(S *-S)^{2} \frac{\partial^{2} C}{\partial S^{2}}=r C
$$

We intend to derive a Logistic nonlinear Black-Scholes-Merton partial differential equations for the European call option with volatility depending on different factors, such as stock price, time, the option price and the respective derivatives. We therefore intend to take into account several effects that are not included in the linear models as well as the recent Nonlinear models. In particular we shall emphasize the logistic Brownian Motion.

The methodology will involve, analysis of the geometric Brownian motion, review of logistic models, Itô' $s$ process and lemma, stochastic volatility models and the derivation of the linear and nonlinear Black-Scholes-Merton partial differential equation. Illiquid markets shall also be analysed. An analysis of stochastic differential equations will also be done extensively. Finally, an attempt will be made to derive the Logistic Non-linear Black-Scholes-Merton Partial Differential Equation.

\section{The Logistic Nonlinear Black-Scholes-Merton Partial Differential Equation}

In this section we use the Geometric Brownian motion equation given by equation 1 above and the random walk in discrete time given by

$$
d \delta=\mu S \delta t+\sigma S \varepsilon \sqrt{\delta t}+O\left(\delta t^{\frac{3}{2}}\right)
$$

with the assumption that the portfolio is revised every $\delta t$ where $\delta t$ is a finite and a fixed time step and that the hedged portfolio has an expected return equal to that from a risk free bank deposit, which is the same as the valuation policy in discrete hedging with no transaction costs.

Suppose the price of an asset follows a Logistic Geometric Brownian motion given by equation (1) given as

$$
d S=\mu S\left(S^{*}-S\right) d t+\sigma S\left(S^{*}-S\right) d Z
$$


then over a sufficiently small time interval $\delta t$ the change in stock price is given by

$$
d \delta=\mu S\left(S^{*}-S\right) \delta t+\sigma S\left(S^{*}-S\right) \varepsilon \sqrt{\delta t}+O\left(\delta t^{\frac{3}{2}}\right)
$$

Where $\varepsilon$ is a random drawing from a normal distribution table.

We set up a hedged portfolio $\Pi$ as

$$
\Pi=C(S, t)-\Delta S
$$

Where $\Delta=\frac{\partial C}{\partial S}(S, t)$. Henceforth we suppress dependance of $\Pi, C, \Delta$ on $t$ over $\delta t$ After a given time $\delta t$ therefore the portfolio becomes

$$
\Pi+\delta \Pi=C(S+\delta S, t+\delta t)-\Delta(S+\delta S)
$$

from which it follows that

$$
\delta \Pi=C(S+\delta S, t+\delta t)-\Delta(S+\delta S)-C(S, t)+\Delta S
$$

Expanding this in Taylor's series we obtain

$$
\begin{aligned}
\delta \Pi & =C \frac{\partial C}{\partial t} \delta t+\frac{\partial C}{\partial S} \delta S+\frac{1}{2} \frac{\partial^{2} C}{\partial S^{2}}(\delta S)^{2}+\ldots-\Delta \delta S \\
& =\sqrt{\delta t} \sigma S\left(S^{*}-S\right) \varepsilon\left(\frac{\partial C}{\partial S}-\Delta\right)+\delta t\left(\frac{\partial C}{\partial t}+\mu S\left(S^{*}-S\right)\left(\frac{\partial C}{\partial S}-\Delta\right)+\frac{1}{2} \sigma^{2} S^{2}\left(S^{*}-S\right)^{2} \varepsilon^{2} \frac{\partial^{2} C}{\partial S^{2}}\right)+\ldots
\end{aligned}
$$

Which has not accounted for the inevitable transaction costs that will be incurred on rehedging. The costs are

$$
k S|C|
$$

The quantity $C$ of the underlying asset that are bought is given by the change in the delta from a given time step to the next:

$$
C \approx \frac{\partial C}{\partial S}(S+\delta S, t+\delta t)-\frac{\partial C}{\partial S}(S, t)
$$

Which can be approximated by

$$
C=\frac{\partial C}{\partial S}+\frac{\partial^{2} C}{\partial S^{2}} \delta S+\frac{\partial^{2} C}{\partial S \partial t} \delta t+\ldots-\frac{\partial C}{\partial S}
$$

Where all derivatives are now evaluated at $(S, t)$. After two terms canceling we get the approximation 
$C \approx \frac{\partial^{2} C}{\partial S^{2}} \delta S \approx \frac{\partial^{2} C}{\partial S^{2}} S \varepsilon \sigma \sqrt{\delta t}$

Subtracting the cost from the change in portfolio value gives a total change of $\delta \Pi=d \Pi-k S|c|$ which is

$$
\begin{aligned}
\delta \Pi & =\sqrt{\delta t} \sigma S\left(S^{*}-S\right) \varepsilon\left(\frac{\partial C}{\partial S}-\Delta\right)+\delta t\left(\frac{\partial C}{\partial t}+\mu S\left(S^{*}-S\right)\left(\frac{\partial C}{\partial S}-\Delta\right)+\frac{1}{2} \sigma^{2} S^{2}\left(S^{*}-S\right)^{2} \varepsilon^{2} \frac{\partial^{2} C}{\partial S^{2}}\right)+ \\
& -k \sigma S^{2}|\varepsilon| \sqrt{\delta t}\left|\frac{\partial^{2} C}{\partial S^{2}}\right|+\ldots
\end{aligned}
$$

The mean of this is

$$
E[\delta \Pi]=\delta t\left(\frac{\partial C}{\partial t}+\mu S\left(S^{*}-S\right)\left(\frac{\partial C}{\partial S}-\Delta\right)+\frac{1}{2} \sigma^{2} S^{2}\left(S^{*}-S\right)^{2} \varepsilon^{2} \frac{\partial^{2} C}{\partial S^{2}}\right)+-k \sigma S^{2} \sqrt{\frac{2 \delta t}{\pi}}\left|\frac{\partial^{2} C}{\partial S^{2}}\right|+\ldots
$$

Because $E[\varepsilon]=0, E\left[\varepsilon^{2}\right]=1$ and $E[|\varepsilon|]=\sqrt{\frac{2}{\pi}}$

We also find that

$$
\begin{aligned}
E\left[(\delta \Pi)^{2}\right]= & \delta t\left[\sigma^{2} S^{2}\left(S^{*}-S\right)^{2} \varepsilon^{2}\left(\frac{\partial C}{\partial S}-\Delta\right)^{2}-2 k \sigma S^{2}\left(S^{*}-S\right)^{2}\left|\frac{\partial^{2} C}{\partial S^{2}}\right| \sigma S\left(S^{*}-S\right)\left(\frac{\partial C}{\partial S}-\Delta\right) \varepsilon|\varepsilon|\right. \\
& \left.+k^{2} \sigma^{2} S^{4}\left(S^{*}-S\right)^{4}\left(\frac{\partial^{2} C}{\partial S^{2}}\right)^{2} \varepsilon^{2}+\ldots\right] \\
& =\delta t\left(\sigma^{2} S^{2}\left(S^{*}-S\right)^{2} \varepsilon^{2}\left(\frac{\partial C}{\partial S}-\Delta\right)^{2}+k^{2} \sigma^{2} S^{4}\left(S^{*}-S\right)^{4}\left(\frac{\partial^{2} C}{\partial S^{2}}\right)^{2}\right)+\ldots
\end{aligned}
$$

since $E[\varepsilon|\varepsilon|]=0$

The variance of the portfolio change is therefore

$$
\begin{aligned}
\operatorname{var}[\delta \Pi] & =E\left[(\delta \Pi)^{2}\right]-(E[\delta \Pi])^{2} \\
& =\delta t\left(\sigma^{2} S^{2}\left(S^{*}-S\right)^{2} \varepsilon^{2}\left(\frac{\partial C}{\partial S}-\Delta\right)^{2}+\left(1-\frac{2}{\pi}\right) k^{2} \sigma^{2} S^{4}\left(S^{*}-S\right)^{4}\left(\frac{\partial^{2} C}{\partial S^{2}}\right)^{2}\right)+\ldots
\end{aligned}
$$

to leading order. For finite hedging period $\delta t$ and finite cost $k$ this cannot generally be made to vanish. However, the variance, or risk, can be minimized by choosing 


$$
\Delta=\frac{\partial C}{\partial S}
$$

With this choice,

$$
E[\delta \Pi]=\delta t\left(\frac{\partial C}{\partial t}+\frac{1}{2} \sigma^{2} S^{2}\left(S^{*}-S\right)^{2} \frac{\partial^{2} C}{\partial S^{2}}-k \sigma S^{2}\left(S^{*}-S\right)^{2} \sqrt{\frac{2 \delta t}{\pi}}\left|\frac{\partial^{2} C}{\partial S^{2}}\right|\right)
$$

to leading order. This quantity is an expectation allowing for the expected amount of transaction costs. We now set this quantity equal to the amount that would have been earned by a risk free account:

$$
\begin{aligned}
& \delta t\left(\frac{\partial C}{\partial t}+\frac{1}{2} \sigma^{2} S^{2}\left(S^{*}-S\right)^{2} \frac{\partial^{2} C}{\partial S^{2}}-k \sigma S^{2}\left(S^{*}-S\right)^{2} \sqrt{\frac{2 \delta t}{\pi}}\left|\frac{\partial^{2} C}{\partial S^{2}}\right|\right) \\
& =r \Pi \delta t=r\left(C-S \frac{\partial C}{\partial S}\right) \delta t
\end{aligned}
$$

On dividing by $\delta$ and rearranging we obtain the Logistic nonlinear Black Scholes Merton partial differential equation given by

$$
\frac{\partial C}{\partial t}+\frac{1}{2} \sigma^{2} S^{2}\left(S^{*}-S\right)^{2} \frac{\partial^{2} C}{\partial S^{2}}-k \sigma S^{2}\left(S^{*}-S\right)^{2} \sqrt{\frac{2}{\pi \delta t}}\left|\frac{\partial^{2} C}{\partial S^{2}}\right|+r S \frac{\partial C}{\partial S}-r C=0
$$

\section{Conclusions and Recommendations}

In this article we have managed to derive a Logistic nonlinear Black Scholes Merton Partial differential equation based on the model with transaction costs. This comes as an advancement in the study of the nonlinear Black Scholes Merton Partial differential equation and in its application in the prediction of future asset prices where transaction costs are considered together with the logistic geometric Brownian motion unlike in previous studies where the Geometric Brownian motion has been used.

We recommend that interested scholars solve the differential equation in order to enhance prediction of future asset prices based on the model derived.

\section{References}

[1] Akira, T. (1996). Mathematical Economics. $2^{\text {nd }}$ Edition; Cambridge university press.

[2] Bachilier L. (1900). Théorié de spéculation Annales scientific de L"E”cole norm sup 111.

[3] Bank P. and Baum D. (2002). Hedging and Portfolio Optimization in Illiquid Financial Markets.; Humboldt University Barlin.

[4] Barles G. and Soner H.M. (1998). Option pricing with transaction costs and Nolinear BlackScholes equation Finance and Stochastics Vol. 2. 
[5] Baum D. (2001). Realisierbarer Portifoliowert in illiquiden Finanzm ̈̈arkten; PhD thesis Department of Mathematics, Humboldt; Universit Äat Berlin.

[6] Beaumont H.P. (2004). Financial Engineering Principles.A unified theory for Financial Product analysis and Valuation; John Wiley \& Sons, Inc, Hoboken, New Jersey.

[7] Black F. and Scholes M. (1973). The pricing of options and cor- porate liabilities; Journal for Political Economics, Vol. 81.

[8] Buchanan J. R. (2006). An Undergraduate Introduction To Finan- cial Mathematics; World Scientific Publishing Co. Pte. Ltd.

[9] Cox J.C.and Ross A. S. (1976). The Valuation of Options for alternative Stochastic Processes; Journal of financial Economics, Vol.3.

[10] Doina C. and Jacques-Louis 1. (2002). Nonlinear Partial Differ- ential Equations And Their Applications; Collége de France Seminar Volume xiv; Elsevier Science B.V.

[11] Ehrhardt M. (2008). Nonlinear Models in Mathematical Finance; Nova Science Publishers.

[12] Frey R. (2000). Market Illiquidity as a source of Model Risk in Dynamic Hedging;Swiss Banking Institute, University of Zuirich; Switzerland.

[13] Frey R. and Pierre P. (2002). Risk Management of Derivatives under Illiquid Markets; Advances in Finance and Stochastics:"Essay in Honour of Dieter Sondermann"; Springer.

[14] Frey R. and Stremme A. (1997). Market Volatility and Feedback effects from Dynamic Hedging; Mathematical Finance, Vol. 7.

[15] Hodges S.D. and Neuberger A. (1989). Optimal replication of contigent claims under transaction costs; Review on future Markets, Vol. 8

[16] Hull J. and White A. (1987). The pricing of options on assets with stochastic volatility Journal of finance, Vol. 42.

[17] Hull C.J. (2000). Option futures and other derivatives $4^{\text {th }}$ edition, prentice; Hall international.

[18] Ito, K. (1944). Stochastic Integrals, Proceedings of the Imperial Academy of Tokyo, Vol. 20.

[19] Jarrow R. (1992). Market manipulation, bubbles, corners and short squeezes; Financial and Qualitative analysis, Vol. 27.

[20] Jarrow R. (1994). Derivatives Securities Markets, Market Manipu- lation and Option Pricing Theory;Journal of Financial and Quanti- tative analysis, Vol. 29.

[21] Jarrow R. and Turnbull S. (1995). Pricing Derivatives on Finan- cial securities subject to Default Risk; Journal of finanance, Vol. 50.

[22] Karuppiah, J. Los, C.A. (2005). Wavelet multiresolution analysis of high-frequency Asian FX rates; International Review of Financial Analysis, Vol. 14.

[23] King, A. C., Billingham, J. and Otto, S. R. (2003). Differential Equations-Linear, Nonlinear, Ordinary, Partial; Cambridge Univer- sity Press.

[24] Leland H. (1985). Option pricing and replication with transaction costs; The Journal of Finance, Vol. 40.

[25] Leland H. and Gennote G. (1990). Market liquidity, hedging and

[26] Crashes; American Economic Review, Vol. 80.

[27] Liu H. and Yong J. (2005). Option Pricing With an Illiquid Un- derlying asseet Market;Journal of Economic Dynamic Control 29; Elsevier B.V.

[28] Lo A. and MacKinlay C. (1997). The Econometrics of FinancialMarkets; Princeton University Press, Princeton New Jersey.

[29] Lo A. and MacKinlay C. (1999). A Non-Random Walk Down WallStreet; Princeton University Press, Princeton New Jersey.

[30] Lungu, E and B. Øksendal (1997). Optimal Harvesting from a Population in a Stochastic Crowded Environment; Mathematical Biosciences, Vol. 145.

[31] Mandelbrot B.B. (1963). The Variation of Certain Speculative Prices; Journal of Business, Vol. 36. 
[32] Mandelbrot B.B. (1967). The Variation of Some Other Speculative Prices; Journal of Business, Vol. 40.

[33] Martin, B. and Andrew R. (2000). An introduction to derivative pricing; Cambridge university press.

[34] Merton R. (1973). The theory of rational option pricing; The Bell of Economics and management science, Vol. 4.

[35] Muller E., Vijay M. and Frank M.B. (1990). New Product Diffus- sion Models in Marketing: Areview and Direction for reserch; Jour- nal of Marketing, Vol. 54.

[36] Muhannad R. N. and Auriélie T. (2007). The Log-logistic Option Pricing Model; Graduate Student Research Paper; Lehigh Univer- sity.

[37] Nyakinda J.O. (2007). Derivation of the Logistic Black Scholes- Merton Partial Differential Equation-A case of Stochastic Volatility; A Masters Thesis in Applied Mathematics, Maseno University.

[38] Onyango S(2003) . Extracting stochastic process from market price data:A pattern recognition approach; PhD Thesis University of Hud- derfield.U.K.

[39] Onyango, S. (2005). On the linear stochastic price adjustment of securities; The East African Journal of statistics, Jomo Kenyatta University press.

[40] Ornstein L.S. and Uhlensbeck G. E (1930). On the theory of theBrownian Motion; The American Physical Society, Rev. 36.

[41] Paul B, Robert L. D. and Glen R. H. (1996). Differential equa- tions; Brooks / Cole publishing company.

[42] Platen E. and Schweizer M. (1998). On feedback effects from hedg- ing derivatives; Mathematical Finance, Vol. 8.

[43] Polyanin, A. D. and Manzhirov A.V. (2007). Handbook of Math- ematics for Engineers and Scientists; Chapman \& Hall. CRC.

[44] Polyanin, A. D. and Manzhirov A.V. (2008). Handbook of ItegralMathematics; Chapman \& Hall. CRC.

[45] Ray R. with Dan P. (1992). Introduction to Differential equations; Jones and Barlett publisher; Boston.

[46] Samuelson, P. A. (1941). The Stability of Equilibrium: Compara- tive Statics and dynamics; Econometrica, Vol. 9. [46] Samuelson, P. A. (1965). Proof that property anticipated prices fluctuate randomly, Industrial Management, Rev. VI.

[47] Savit R. (1988). When random is not random:An introduction to chaos in market prices; The Journal of future markets, Vol. 8.

[48] Savit R. (1989). Nonlinearities and chaotic effects in option prices; The Journal of future markets, Vol. 8.

[49] Sergio M. F.\& Fabozzi F. J. (2004). The Mathematics of Financial Modeling and Investment Management; John Wiley \& Sons, Inc., Hoboken, New Jersey Published simultaneously in Canada.

[50] Sheldon M. R (1999). An introduction to mathematics of finance; University of Carlifonia Berkeley, Cambridge university press.

[51] Sicar R. and Papanicolaou (1998). General Black Scholes Ac- counting for Increased Market Volatility from Hedging Strategies; Ap- plied mathematical finance, Vol. 5.

[52] Van Djik D. and Franses P. (2000). Non-linear time series model in emperical finance; Cambridge University Press, Cambridge, United Kingdom.

[53] Verhulst, P.F (1838). Notice sur la loi que la population suit dans son accroissement, Correspondence Mathmatique et physique, Vol.10.

[54] Whalley E. A. (1998). Option pricing with transaction costs; A PhDthesis, University of Oxford.

[55] Whalley E. A. and Wilmott P. (1997). An asymptotic analysis of an optimal hedging model for option pricing with transaction costs; Mathematical Finance, Vol. 7. 
[56] Wilmott P, Howlson S and Dewayne J. (1995). The Mathematics of Financial Derivatives; Pass Syndicate of The University of Cambridge.

[57] Wilmott P. (1998). Derivatives-The Theory and Practice of Financial Engineering; John Wiley and Sons Ltd, Baffin Lane. Chichester, West Sussex 1019 IUD. England.

[58] Wilmott P. (2006). Paul Wilmott on Quantitative Finance; John Wiley \& Sons Ltd, The Atrium, Southern Gate, Chichester, West Sussex PO19 8SQ, England. (2005) found that..." OR "In a similar study, Jones and Smith (1999) found that...".

*Corresponding author.

E-mail address: jnyakindas@ yahoo.com 